\title{
ESTUDIO DE TOXICIDAD DE COMPONENTES SOLUBLES DEL GRITS SOBRE CUATRO ESPECIES VEGETALES
}

Mgter. Carlos S. Jejerr' L.Q.I. Carla G. Silva ${ }^{1}$;Mgter. Jeannette A. Bauman ${ }^{1}$

\section{RESUMEN}

El grits es un residuo alcalino producido en el proceso Kraft de la industria celulósico papelera, generándose en la etapa de recuperación química, durante el proceso de caustificación del licor verde. Sus componentes mayoritarios son los óxidos de calcio y magnesio, conteniendo además metales pesados en bajas concentraciones. El residuo utilizado en el estudio provino de una industria papelera productora de pulpa kraft sin blanquear de la provincia de Misiones.

El objetivo del estudio ha sido realizar ensayos de toxicidad aguda de los componentes solubles del grits, empleando semillas de zanahoria, pepino, lechuga y repollo. Se evaluaron los efectos sobre la inhibición de la elongación radicular de las plántulas en soluciones acuosas de grits en un rango de concentraciones entre $1 \mathrm{~g} / \mathrm{L}$ y $0,01 \mathrm{~g} / \mathrm{L}$.

Se determinó, mediante el análisis de comparación de medias, la mínima concentración a la cual se observó una diferencia estadísticamente significativa $(\mathrm{p}<0,05)$ respecto del control (LOEC), siendo los valores obtenidos $1 \mathrm{~g} / \mathrm{L} ; 0,1 \mathrm{~g} / \mathrm{L}$ y $0,03 \mathrm{~g} / \mathrm{L}$ para la inhibición radicular en plántulas de pepino, zanahoria y lechuga respectivamente.
En las plántulas de repollo no se observaron diferencias significativas $(p>0,05)$ con respecto al control en la inhibición radicular para las concentraciones ensayadas.

La plántula de lechuga a partir del valor LOEC presentó exaltación de la elongación radicular, mientras que las plántulas de pepino y zanahoria presentaron inhibición radicular a partir del valor LOEC, siendo la más sensible al compuesto ensayado la plántula de zanahoria.

Palabras claves: fitotoxicidad-bioensayos-grits-pulpado kraft

\section{INRODUCCIÓN}

La toxicidad de una sustancia química depende del efecto, el tiempo de exposición, la dosis y del organismo con el cual entra en contacto. El grits es un residuo alcalino producido por el proceso Kraft de la industria celulósico papelera que se genera en la etapa de recuperación química, durante el proceso de caustificación del licor verde (Lozano, 2008). Este residuo se caracteriza por ser alcalino y estar formado mayoritariamente por óxidos de calcio y magnesio, conteniendo además metales pesados como cromo, cobre y zinc en bajas concentracio-

${ }^{1}$ Programa Efluentes Industriales y Urbanos-FCEQyN-UNaM - Campus Universitario. Módulo de Ingeniería. Posadas-Misiones -Berón de Astrada 3118 Posadas. Misiones CP 3300 cjejer@gmail.com 
nes. Debido a sus componentes alcalinos se ha planteado la posibilidad de su utilización como enmienda de acidez en suelos de la provincia de Misiones, permitiendo a los productores de escasos recursos disponer de una enmienda a bajo costo (Jejer et al, 2011). En este sentido los productos utilizados en la practica agrícola son caliza $(\mathrm{CaCO} 3)$ y Dolomita $(\mathrm{Ca} \mathrm{Mg}(\mathrm{CO} 3) 2)$ (Barber, 1984; Millán et al, 2010).

La caracterización química del grits no resulta suficiente para determinar su potencial toxicidad, ya que no contempla el comportamiento sinérgico o antagónico de los distintos componentes en el sistema residuo-plantas, por lo tanto resulta necesario evaluar los efectos tóxicos empleando bioensayos (Celis et al., 2006).

El ensayo de toxicidad aguda con semillas es una prueba estática en la que se evalúan, al finalizar la prueba, la inhibición en la germinación y/o inhibición en la elongación radicular. $\mathrm{El}$ valor $\mathrm{LOEC}$ es la mínima concentración a la cual se observa una diferencia estadísticamente significativa respecto del control (agua destilada) y se determina mediante el análisis de comparación de medias (Bowers et al, 1997).

El objetivo del trabajo fue la evaluación de la fitotoxicidad de los componentes solubles del grits con semillas de zanahoria (Daucus carota), pepino (Cucumis sativus), repollo (Brassica oleracea) y lechuga (Lactuca sativa), teniendo en cuenta las diferencias de sensibilidad que pueden presentar las especies vegetales frente a determinados compuestos (Celis et al., 2006; Abou Auda et al., 2010).

\section{MATERIALES Y MÉTODOS}

E1 "grits", empleado en los ensayos, se obtuvo de una planta industrial de celulosa productora de pulpa "kraft" sin blanquear de la Provincia de Misiones. La recolección del material se realizó extrayendo muestras compensadas en el transcurso de cuatro semanas, conformadas por sub-muestras puntuales de $500 \mathrm{~g}$ recolectadas cada ocho horas.

Se preparó una solución cuya concentración de grits correspondió a su solubilidad a la temperatura de $25^{\circ} \mathrm{C}$.

Los ensayos de toxicidad aguda consistieron en colocar un papel de filtro saturado con $5 \mathrm{ml}$ de solución del material a ensayar en cada placa de Petri y sobre él se depositaron 10 semillas. Este ensayo se realizó por triplicado y para cada una de las especies vegetales. Las placas se mantuvieron a una temperatura de $24 \pm 2^{\circ} \mathrm{C}$ durante 5 días. $\mathrm{Al}$ finalizar el ensayo se midió con regla milimetrada la longitud de la radícula en cada una de las plántulas (IRAM 29114:2008 y EPA 712-C-96-154:1996).

$\mathrm{El}$ efecto de las concentraciones de grits, sobre la elongación radicular de las especies expuestas, se evaluó en comparación a la respuesta de estas, al ser sometidas al control negativo, agua destilada, sujetas a las mismas condiciones de ensayo. Se calculó el porcentaje de inhibición relativo de la elongación radicular, determinándose mediante el análisis de comparación de medias, la mínima concentración a la cual se observó una diferencia estadísticamente significativa del control negativo (LOEC), con un nivel de significancia del $95 \%$.

\section{RESULTADOS Y DISCUSIÓN}

De la comparación de medias de la inhibición radicular para las especies de semillas en estudio (figura 1), se puede observar 
que las plántulas de repollo no presentan diferencias significativas $(p>0,05)$ con respecto al control para las concentraciones ensayadas. Mientras que las plántulas de pepino, zanahoria y lechuga presentan una diferencia estadísticamente significativa $(\mathrm{p}<0,05)$ respecto del control $(\mathrm{LOEC})$, siendo los valores obtenidos $1 \mathrm{~g} / \mathrm{L} ; 0,1 \mathrm{~g} / \mathrm{L}$ y $0,03 \mathrm{~g} / \mathrm{L}$ para la inhibición radicular respectivamente. Se consideró estimulación de la elongación radicular a los valores negativos en el porcentaje de inhibición. La

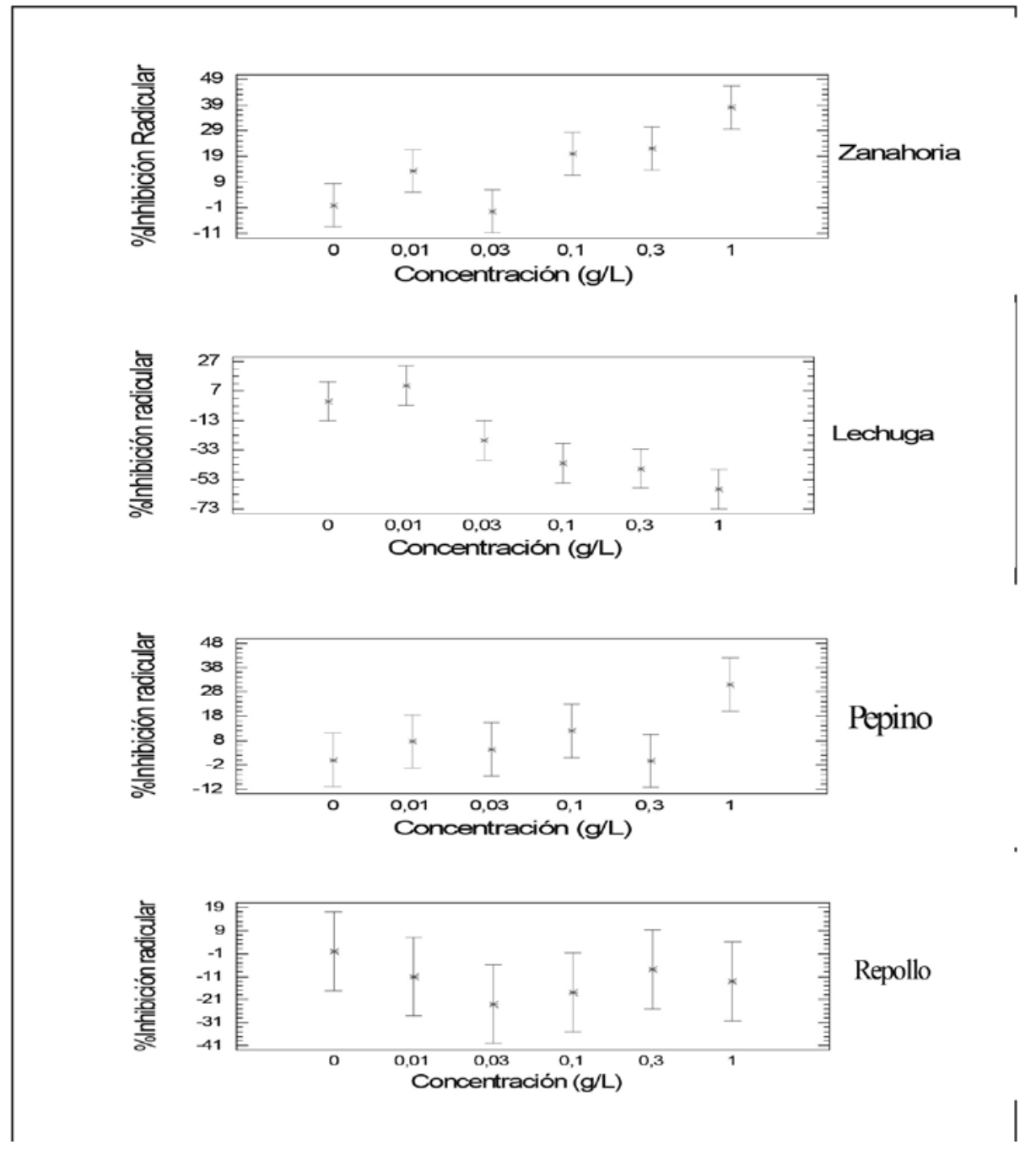

Figura 1. Comparación de medias del porcentaje de inhibición radicular con un nivel de significancia del 5\% para las cuatro especies de semillas

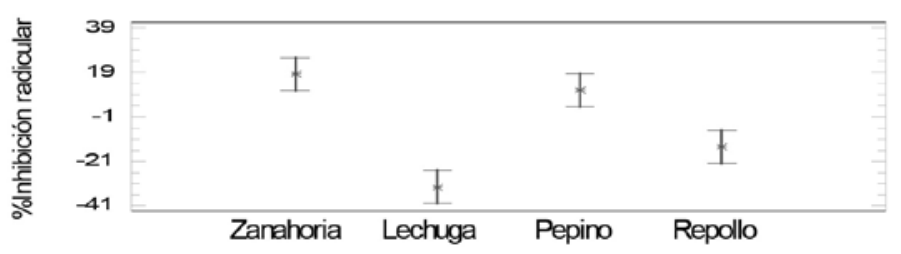

Figura 2. Comparación de medias con intervalo de confianza del 95\% 
inhibición en la elongación de la radícula constituye un indicador subletal sensible para evaluar efectos biológicos (Sobrero et al., 2004).

La plántula de lechuga presentó exaltación de la elongación radicular, mientras que las plántulas de pepino y zanahoria presentaron inhibición radicular a partir del valor LOEC, siendo la más sensible al compuesto ensayado, la plántula de zanahoria (figura 2). Según Intawongse and Dean, 2006 y Mohamad and Emad, 2010; el cinc provoca disminución en la elongación radicular en zanahorias.

\section{CONCLUSIONES}

No se observó fitotoxicidad de los componentes solubles del grits sobre las plántulas de repollo y lechuga, al evaluar los efectos sobre la inhibición radicular con un nivel de significancia del 95\%. Se observó que las dos especies afectadas, por los componentes solubles, fueron el pepino y la zanahoria, siendo esta última la especie más sensible.

\section{REFERENCIAS}

1- Abou Auda, M.; El Shakh Ali, E. 2010. Cadmiun and zinc toxicity effects on growth and mineral nutrients of carrot (Daucus carota). Pak. J. Bot. 42 (1) p: 341-351.

2- Barber, SA. 1984. Liming material and practices. In Adams F., Ed. Soil acidity and liming, 2 ed., Madison, Wisconsin, USA, ASA Inc. p. 171-209.

3- Bowers, N.; Pratt J.R.; Beeson D.; Lewis M. 1997. Comparative evaluation of soil toxicity using lettuce seeds and soil ciliates. Environ Toxicol and Chemistry 16(2), 207-213.

4- Celis, J.; Sandoval, M.; Zagal, E.; Briones, M. 2006. Efecto de la adición de biosolidos urbanos y de salmonicultura sobre la germinación de semillas de lechuga (Lactuca sativa L.) en un suelo patagónico. Revista de la ciencia del suelo y nutrición vegetal 6 (3): 13-25. ISSN 0718-2791.

5- EPA 712-C-96-154. 1996. Ecological Effects Test Guidelines. OPPTS 850.4200. Seed Germination/Root Elongation ToxicityTest.

6- IRAM 29114. 2008. Método de ensayo de toxicidad aguda con semillas de lechuga (Lactuca sativa). Método en papel.

7- Intawongse, M.; Dean J. 2006. Uptake of heavy metals by vegetable plants grown on contaminated soil and their biovalability in the human gastrointestinal tract. Food additives and contaminants. 23: 36-48.

8- Jejer, C.; Sosa, A.; Iwasita, B.; Covinich, L.; Monzón F. 2011. Evaluación de un residuo de la industria de celulosa kraft como enmienda de acidez del suelo. Libro de resúmenes. VIII Jornadas científico tecnológicas. p: 191. ISBN: 978-950-766-081-8.

9- Lozano, B. 2008. Proceso kraft de producción de pasta de papel. Ingeniería química. o 458. p: 138-144.

10- Millán, G.; Vázquez, M.; Terminiello, A.; Santos Sbuscio, D. 2010. Efecto de las enmiendas básicas sobre el complejo de cambio en algunos suelos ácidos de la región pampeana. Ciencia del Suelo 28(2). 131-140

11- Mohamad A. A.; and Emad E1 S. A. 2010. Cadmium and zinc toxicity effects on growth and mineral nutrients of carrot (Daucus carota). Pak. J. Bot., 42 (1). 341-351.

12- Sobrero, María Cecilia y Ronco, Alicia. 2004. Ensayos para agua dulce. Capítulo 4. Ensayo de toxicidad aguda con semillas de lechuga. Pág. 55-67. 